\title{
Pengelasan Pada Stainless Steel Dengan Tipe Yang Berbeda Menggunakan Resistance Spot Welding untuk Aplikasi Gerbong Kereta
}

\section{Mochammad Karim Al Amin*, Suthoni Yoga Firiambodo, Endang Pudji Purwanti, Eriek Wahyu Restu Widodo, Dika Anggara}

Teknik Bangunan Kapal, Politeknik Perkapalan Negeri Surabaya, Jl. Teknik Kimia, Keputih, Kec. Sukolilo, Kota SBY, Jawa Timur 60111

*E-mail: karim@ppns.ac.id

Diterima: 11-07-2021; Direvisi: 18-11-2021; Dipublikasi: 30-12-2021

\begin{abstract}
Abstrak
Mode transportasi yang memadai mempunyai peran penting dalam pembangunan suatu wilayah. Salah satu mode transportasi yang dapat menunjang peningkatan produktivitas suatu wilayah adalah kereta api. Guna memenuhi kebutuhan kereta api yang terus meningkat maka diperlukan inovasi dan penelitian dalam produksi setiap bagian dari kereta api agar menghasilkan produk dengan mutu tinggi. Salah satu bagian utama kereta api adalah dinding samping (side wall). Proses penyambungan material pada side wall digunakan proses pengelasan resistance spot welding. Salah satu jenis proses pengelasan yang banyak digunakan di dunia industri Kereta Api adalah proses resistance spot welding. Proses pengelasan ini mempunyai banyak keunggulan pada pengelasan pelat tipis dengan menggunakan sambungan tumpang yang diaplikasikan pada side wall kereta api. Penelitian ini dilakukan dengan tujuan untuk mengetahui pengaruh variasi parameter pengelasan yang meliputi current, weld time, dan pulsation terhadap shear strength, struktur mikro dan diameter nugget. Material yang digunakan adalah material SA-240 tipe 304 dan SA-240 tipe 201 dengan ketebalan $2 \mathrm{~mm}$ untuk material SA-240 tipe 304 dan tebal $3 \mathrm{~mm}$ untuk material SA-240 tipe 201. Pengujian shear strength diperoleh parameter resistance spot welding semakin tinggi, maka nilai shear strength juga semakin tinggi. Strukturmakro didapatkan semakin tinggi current, weld time, dan pulsation, maka nugget semakin lebar. Sedangkan pada hasil uji mikro pada daerah base metal struktur yang tebentuk adalah austenite, sedangkan pada daerah HAZ dan weld metal adalah struktur ferrit dan austenite. Ukuran butir pada daerah HAZ yang semakin mendekat ke daerah weld metal ukuran butirnya menjadi semakin besar. Struktur mikro yang terbentuk pada weld metal bentuknya memanjang (columnar grains) ke daerah yang mengalami pembekuan paling akhir.
\end{abstract}

Kata kunci: Metalografi; Parameter Pengelasan; Resistance spot welding.

\begin{abstract}
The sufficient transportation's mode have important role in developing of a region. One of transportation's mode which can support for increasing the productivity of a region is train. For fulfulling the demand of train which increase, so it is needed the innovations and researchs in the production of each part of train in order to produce the high quality product. One of the main part of train is side wall. The assembling process of side wall's material was used resistance spot welding. One of the most used welding process in the thain industry is resistance spot welding. This welding process has many advantages in the welding for sheet by using overlap joint for side wall of train. This research was conducted to study the effect of welding parameter such as current, weld time, and pulsation to shear strength, microstructure dan nugget diameter. The materials were 304 and 201 type of SA-240 with $2 \mathrm{~mm}$ and $3 \mathrm{~mm}$ thickness respectively. The shear strength test was obstained higher resistance spot welding parameter, higher shear strength. The macrostructure was obstained that higher current, weld time, and pulsation made wider nugget.Whereas, the microstructure of base metal was formed austenite, on the other areas of HAZ and weld metal were formed ferrite and austenite. Grain size at the HAZ where nearby weld metal was bigger. The microstructure which formed at weld metal was columnar grains to the area where the last solidification was occurred.
\end{abstract}

Keywords: Metalography; Welding Parameter; Resistance spot welding.

\section{Pendahuluan}

Seiring perkembangan teknologi dan persaingan didunia kerja yang semakin ketat membuat setiap manusia juga dituntut selalu cepat dan tepat dalam menjalankan segala aktifitas. Untuk menunjang segala aktifitas tersebut setiap manusia membutuhkan sarana dan prasana pendukung agar segala aktifitasnya dapat berjalan dengan lancar. Pendukung tersebut dapat berupa mode transportasi yang memadai, karena mode transportasi mempunyai peran penting dalam 
pembangunan suatu wilayah. Salah satu mode transportasi yang dapat menunjang peningkatan produktivitas suatu wilayah adalah kereta api [1]. Untuk memenuhi kebutuhan kereta api yang terus meningkat maka diperlukan inovasi dan penelitian dalam produksi setiap bagian dari kereta api agar menghasilkan produk dengan mutu tinggi. Salah satu bagian utama kereta api adalah dinding samping (side wall) [2].

Dalam produksi dinding samping kereta api digunakan material stainless steel, hal ini bertujuan agar dinding samping kereta tidak mudah terkorosi. Jenis material stainless steel yang digunakan adalah SA-240 tipe 201 dan SA-240 tipe 304, karena tipe ini mempunyai sifat ketahanan korosi yang baik [3]. Proses penyambungan material pada side wall menggunakan proses pengelasan resistance spot welding. Proses resistance spot welding merupakan bentuk pengelasan tahanan dimana suatu las akan terbentuk pada titik benda kerja yang berada diantara kedua elektroda [4]. Saat proses penekanan arus dialirkan sesuai dengan arus pengelasan yang tertera dalam welding procedure specification atau parameter yang disarankan oleh produsen mesin las spot tersebut. Cara penyambungan material dalam bentuk lembaran yang efisien untuk aplikasi industri otomotif dan kereta api adalah dengan menggunakan resistance spot welding [5].

Dalam proses resistance spot welding terdapat sebuah siklus pengelasan atau welding cycle, siklus pengelasan dalam resistance spot welding meliputi proses waktu penekanan (squezze time), waktu pengelasan (weld time), waktu penahanan (hold time) dan waktu selesai (off time) [6]. Resistance spot welding dapat mengalami kegagalan jika dalam pelaksanaannya tidak memperhatikan pemilihan besar kuat arus listrik, lama waktu pengelasan, dan jenis material yang dilas. Terdapat 2 jenis kegagalan dalam resistance spot welding yaitu interfacial failure $(I F)$ dan pull out failure (PF). Interfacial failure adalah terjadinya keretakan atau kerusakan pada daerah fusi, sedangkan pull out failure adalah terjadinya kerusakan pada sekitar daerah fusi yaitu pelat mengalami sobek. Dalam aplikasinya di produk, jenis kegagalan yang diharapkan adalah pull out failure. Karena jenis kegagalan ini mempunyai nilai geser yang lebih tinggi. Untuk mendapatkan nilai geser yang tinggi maka ukuran diameter nugget lasan yang sangat berpengaruh. Nugget lasan pada material yang berbeda ketebalan akan memberikan diameter nugget yang tidak simetris [7].

Hingga saat ini penelitian tentang optimalisasi resistance spot welding agar mendapat hasil nilai uji geser yang lebih baik terus dilakukan. Salah satu penelitian tersebut dilakukan oleh Manoj Raut [8]. Dalam penelitian yang dilakukan Manoj dkk menggunakan variasi arus pengelasan, tekanan elektroda dan waktu pengelasan. Dari hasil penelitian yang telah dilakukan menyebutkan bahwa parameter sangat berpengaruh dalam menghasilkan hasil pengelasan yang sangat baik. Salah satunya adalah tekanan elektroda, dengan peningkatan tekanan elektroda akan menyebabkan diameter nugget semakin kecil. Hal tersebut disebabkan karena semakin tinggi tekanan menyebabkan titik las semakin kecil karena panas dan arus listrik bepindah ke area yang lebih luas.

Penelitian lainnya yang dilakukan oleh Dicky Prastya menunjukkan semakin lama weld time pada proses resistance spot welding maka akan menghasilkan diameter nugget yang semakin besar juga. Dari 5 variasi arus yang digunakan 0,28 detik; 0,32 detik; 0,36 detik; 0,40 detik dan 0,44 detik, yang menghasilkan diameter nugget paling besar adalah weld time 0,44 detik, dengan ukuran diameter nugget sebesar $7,73 \mathrm{~mm}$. Pada variasi tersebut juga didapatkan nilai uji geser tertinggi yaitu sebesar 713,06 N/mm² [9].

Dari beberapa penjelasan referensi di atas, maka perlu dilakukan penentuan parameter pengelasan yang tepat untuk proses resistance spot welding agar menghasilkan kekuatan sambungan pengelasan yang baik. Penelitian ini dilakukan pengelasan dengan variasi welding current, weld time dan pulsation pada sambungan material SA-240 tipe 201 dan SA240 tipe 304 terhadap shear strength dan metalografi. 


\section{Material dan metodologi}

Dalam penelitian ini jenis sambungan yang digunakan adalah lap joint atau sambungan tumpang yang menyesuaikan dengan kondisi aktual pada side wall kereta api. Sedangkan jenis materialnya SA-240 tipe 201 dan SA-240 tipe 304, dengan pemilihan material tersebut diharapkan dapat menghasilkan kekuatan sambungan yang baik ditinjau dari uji shear strength dan metalografi (uji makro dan mikro). Material benda kerja yang dilakukan pengelasan dipotong dengan dimensi panjang $160 \mathrm{~mm}$, lebar $40 \mathrm{~mm}$ dan tebal $3 \mathrm{~mm}$ untuk material SA-240 tipe 201, sedangkan tebal $2 \mathrm{~mm}$ pada SA240 tipe 304 [10]. Bentuk sambungan material yang dilas dapat dilihat pada Gambar 1.

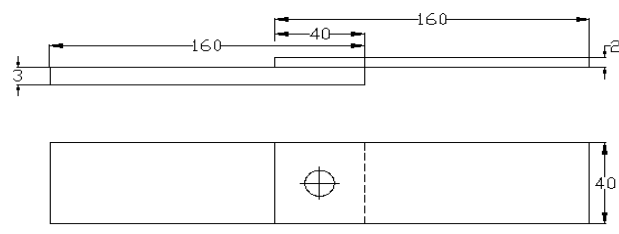

\section{Gambar 1. Dimensi Benda Kerja Resistance spot welding}

Nilai kekuatan tarik material yang didapatkan dari sertifikat material yaitu sebesar 810 MPa untuk material SA-240 tipe 201, sedangkan untuk material SA-240 tipe 304 sebesar 618 MPa. Komposisi kimia kedua material tersebut dapat dilihat pada Tabel 1.

Tabel 1. Komposisi Kimia Material

\begin{tabular}{cccccccccc}
\hline \multirow{2}{*}{ Jenis Material } & \multicolumn{10}{c}{ Komposisi Kimia (\%) } \\
\cline { 2 - 10 } & $\mathbf{C}$ & $\mathbf{M n}$ & $\mathbf{S}$ & $\mathbf{P}$ & $\mathbf{S i}$ & $\mathbf{N i}$ & $\mathbf{C r}$ & $\mathbf{C u}$ & $\mathbf{N}$ \\
\hline $\mathbf{2 0 1}$ & 0.123 & 9.8 & 0.003 & 0.092 & 0.57 & 0.53 & 16.7 & 1.15 & 0.15 \\
\hline $\mathbf{3 0 4}$ & 0.055 & 0.89 & 0.005 & 0.041 & 0.28 & 8.02 & 18.15 & - & 0.06 \\
\hline
\end{tabular}

Material yang akan dilas dibersihkan terlebih dahulu permukaannya dari pengotor agar hasil sambungan dapat menyatuh sempurna, setelah itu material diletakkan pada mesin resistance spot welding. Sebelum proses pengelasan setiap benda kerja dilakukan, parameter pengelasannya diatur terlebih dahulu sesuai dengan variasi yang ada pada Tabel 2 dan kemudian dilakukan pengelasan.

Tabel 2. Parameter Pengelasan

\begin{tabular}{cccc}
\hline Eksperimen & Curren $(\boldsymbol{k A})$ & Weld Time $($ cycle $)$ & Pulsation (time $)$ \\
\hline $\mathbf{1}$ & 10 & 17 & 0 \\
\hline $\mathbf{2}$ & 10 & 22 & 1 \\
\hline $\mathbf{3}$ & 10 & 27 & 2 \\
\hline $\mathbf{4}$ & 10.5 & 17 & 2 \\
\hline $\mathbf{5}$ & 10.5 & 22 & 0 \\
\hline $\mathbf{6}$ & 10.5 & 27 & 2 \\
\hline $\mathbf{7}$ & 11 & 17 & 0 \\
\hline $\mathbf{8}$ & 11 & 22 & 1 \\
\hline $\mathbf{9}$ & 11 & 27 &
\end{tabular}


Setelah proses pengelasan selesai langkah selanjutnya adalah material dilakukan uji geser (shear strength) dan pengujian metalografi. Pengujian shear strength dilakukan dengan tujuan untuk mengetahui nilai uji geser sambungan akibat adanya beban geser. Adapun langkah-langkahnya yaitu proses pembersihan permukaan material dengan gerinda halus agar dapat dicekam dengan sempurna oleh ragum. Kemudian memberi tanda sesuai variasi yang dilakukan dan mengukur dimensi material uji dan dicatat pada form pengujian. Setelah persiapan selesai, material diuji diletakkan pada ragum dengan mengatur jarak antar ragum bawah dan atas. Jika material sudah siap, atur beban dan pencatat grafik pengujian kemudian lakukan pengujian hingga mencapai titik ultimate dan turun hingga mengalami fracture. Proses pengujian shear strength dapat dilihat pada Gambar 2.

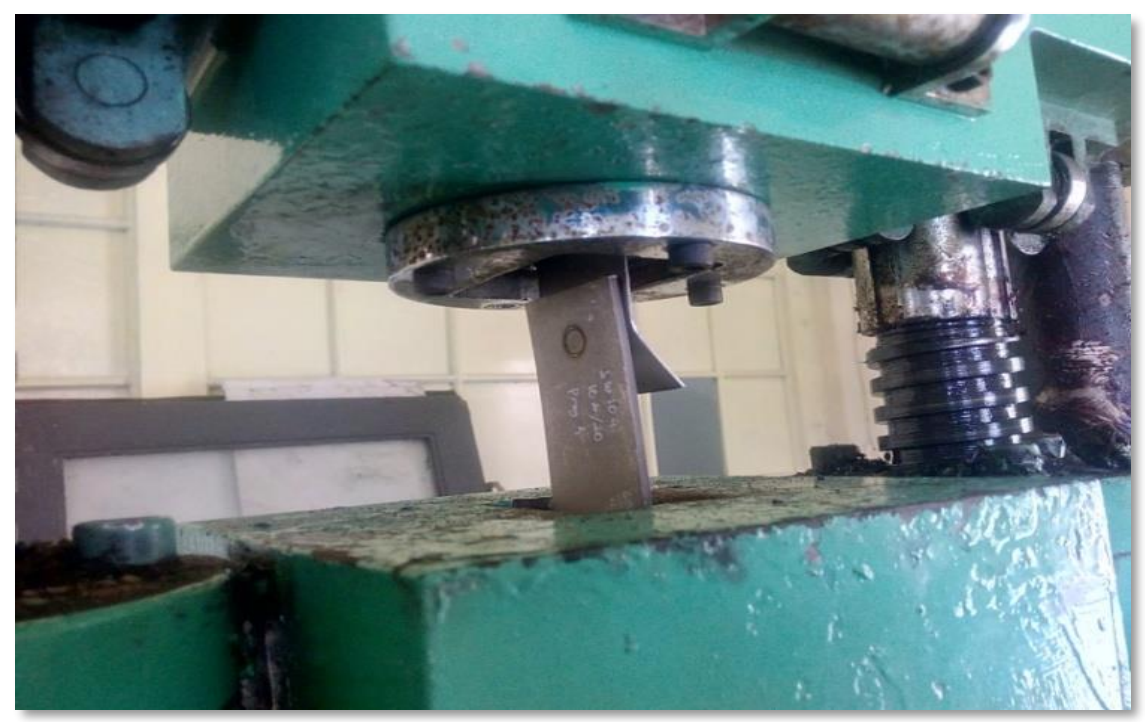

Gambar 2. Proses Pengujian Shear Strength

Analisa selanjutnya adalah pengujian metalografi yaitu pengujian struktur mikro dan makro, struktur mikro yang diamati adalah daerah logam induk, heat affected zone dan logam las. Dalam persiapannya ada beberapa tahapan yang meliputi proses pemotongan, penggerindaan, pemolesan serta proses etsa. Proses pemotongan menggunakan mesin gergaji yang dialiri dengan cairan pendingin agar temperatur material tetap terjaga dan tidak berubah strukturnya. Selanjutnya adalah proses penggerindaan dan pemolesan, penggerindaan dengan gerinda tangan dilakukan untuk membersihkan daerah yang kasar bekas proses pemotongan. Kemudian proses pemolesan menggunakan polishing machine dan kertas gosok dengan tingkat kekasaran 320,600, 800, 1000, 2000, dan 5000, untuk mendapatkan hasil maksimal dilangkah terakhir dilakukan polishing menggunakan kain wool.

Proses etsa dilakukan dengan menyiapkan alat seperti pipet, cawan kimia, dan hand dryer. Cairan etsa yang digunakan adalah larutan $\mathrm{HNO}_{3} 1 \mathrm{ml}$ dicampur dengan $\mathrm{HCl} 3 \mathrm{ml}$ [10]. Celupkan benda uji yang akan diamati struktur mikro kedalam larutan tersebut selama beberapa detik dan angkat benda uji, kemudian siram dengan air dan keringkan dengan hand dryer. Pengujian struktur mikro menggunakan mikroskop optic, sedangkan untuk pengujian makro menggunakan kamera DSLR. Dalam pengujian makro, ukuran lebar nugget dari hasil resistance spot welding harus sesuai dengan syarat keberterimaan seperti yang ada pada Tabel 3 . 
Tabel 3. Syarat Keberterimaan Lebar Nugget [10]

\begin{tabular}{lc}
\hline \multicolumn{1}{c}{ Material Thickness, in $(\mathbf{m m})$} & Weld Nugget Width \\
\hline$<0.010(0.25)$ & $6 \mathrm{t}$ \\
\hline$\geq 0.010(0.25)$ and $<0.020(0.50)$ & $5 \mathrm{t}$ \\
\hline$\geq 0.020(0.50)$ and $<0.040(1.00)$ & $4 \mathrm{t}$ \\
\hline$\geq 0.040(1.00)$ and $<0.069(1.75)$ & $3 \mathrm{t}$ \\
\hline$\geq 0.069(1.75)$ and $<0.100(2.54)$ & $2.50 \mathrm{t}$ \\
\hline$\geq 0.100(2.54)$ and $<0.118(3.00)$ & $2.25 \mathrm{t}$ \\
\hline$\geq 0.118(3.00)$ and $<0.157$ & $2 \mathrm{t}$ \\
\hline
\end{tabular}

\section{Hasil dan pembahasan}

\subsection{Pengujian Shear Strength}

Pengujian shear strength dilakukan dengan tujuan untuk mengetahui sifat mekanik suatu sambungan pengelasan atau material seperti kekuatan geser, tegangan luluh dan regangan. Dalam pengujian shear strength setiap variasi dilakukan pengujian sebanyak 3 kali, sehingga pada proses pengelasan juga dilakukan sebanyak 27 sambungan. Berikut merupakan hasil pengujian shear strength yang dapat dilihat pada Tabel 4.

Tabel 4. Hasil Pengujian Shear Strenght

\begin{tabular}{|c|c|c|c|c|c|c|c|c|c|}
\hline \multirow[b]{2}{*}{ Eks } & \multicolumn{3}{|c|}{ Variabel } & \multicolumn{3}{|c|}{ Hasil Shear Strength (kgf) } & \multirow{2}{*}{$\begin{array}{c}\text { Rata- } \\
\text { rata } \\
\text { (Kgf) }\end{array}$} & \multirow{2}{*}{$\begin{array}{c}\text { Rata- } \\
\operatorname{rata}(\mathbf{N})\end{array}$} & \multirow[b]{2}{*}{ Remark } \\
\hline & $\begin{array}{c}\text { Current } \\
\text { (kA) }\end{array}$ & $\begin{array}{c}\text { Weld Time } \\
\text { (Cycle })\end{array}$ & $\begin{array}{c}\text { Pulsation } \\
\text { (time ) }\end{array}$ & $\begin{array}{c}\text { Replika } \\
1\end{array}$ & $\begin{array}{c}\text { Replika } \\
2\end{array}$ & $\begin{array}{c}\text { Replika } \\
3\end{array}$ & & & \\
\hline $\mathbf{1}$ & 10 & 17 & 0 & 2240 & 2200 & 2220 & 2220.00 & 21756.00 & Accepted \\
\hline 2 & 10 & 22 & 1 & 2720 & 2350 & 2650 & 2573.33 & 25218.67 & Accepted \\
\hline 3 & 10 & 27 & 2 & 2850 & 2790 & 2650 & 2763.33 & 27080.67 & Accepted \\
\hline 4 & 10.5 & 17 & 1 & 2700 & 2700 & 2650 & 2683.33 & 26296.67 & Accepted \\
\hline 5 & 10.5 & 22 & 2 & 2830 & 2800 & 2850 & 2826.67 & 27701.33 & Accepted \\
\hline 6 & 10.5 & 27 & 0 & 2800 & 2750 & 2780 & 2776.67 & 27211.33 & Accepted \\
\hline 7 & 11 & 17 & 2 & 2960 & 2750 & 2740 & 2816.67 & 27603.33 & Accepted \\
\hline 8 & 11 & 22 & 0 & 2400 & 2520 & 2550 & 2490.00 & 24402.00 & Accepted \\
\hline 9 & 11 & 27 & 1 & 2980 & 3200 & 3050 & 3076.67 & 30151.33 & Accepted \\
\hline
\end{tabular}

Dari Tabel 4 diperoleh hasil pengujian shear strength yang semuanya diterima karena nilainya diatas syarat keberterimaan yaitu sebesar $13460 \mathrm{~N}$ dengan rincian bahwa $1 \mathrm{kgf}$ sama dengan 9,8 $\mathrm{N}$ [10]. Untuk nilai rata-rata pengujian shear strength terendah berada pada eksperimen 1 dengan variasi current sebesar $10 \mathrm{kA}$, weld time 17 cycle dan pulsation 0 time. Sedangkan nilai rata-rata tertinggi untuk pengujian shear strength adalah eksperimen 9 dengan variasi current sebesar $11 \mathrm{kA}$, weld time 27 cycle dan pulsation 1 time. Dari hasil pengujian shear strength ini juga dapat disimpulkan jika setiap parameter pengelasan yang berupa current, weld time dan pulsation pada material stainless steel SA-240 tipe 201 dan SA-240 tipe 304 mempunyai pengaruh terhadap hasil pengujian shear strength hal itu dapat dilihat disetiap ada perubahan parameter tersebut terdapat perubahan nilai shear strength. Menurut Karmiadji dalam penelitiannya kontribusi arus, lama pengelasan dan tekanan pada pengelasan material baja SPCC270D dan material baja SCGA juga berpengaruh 
sebesar I : $67.39 \%$; Wt : 30.06\% ; P : 1.65\% [11]. Perlu diperhatikan jika pemilihan arus yang terlalu besar juga akan menyebabkan masukkan panas terlalu tinggi yang menyebabkan overheating, hal ini juga menyebabkan kerusakan pada sambungan [12].

\subsection{Pengujian Makro}

Pengujian makro dilakukan untuk mengetahui dimensi nugget hasil resistance spot welding akibat pengaruh current, weld time dan pulsation. Pengujian makro yang dilakukan pada penelitian ini adalah benda uji yang mempunyai nilai shear strength terendah dan shear strength tertinggi. Hasil pengujian makro dapat dilihat pada Gambar 3.

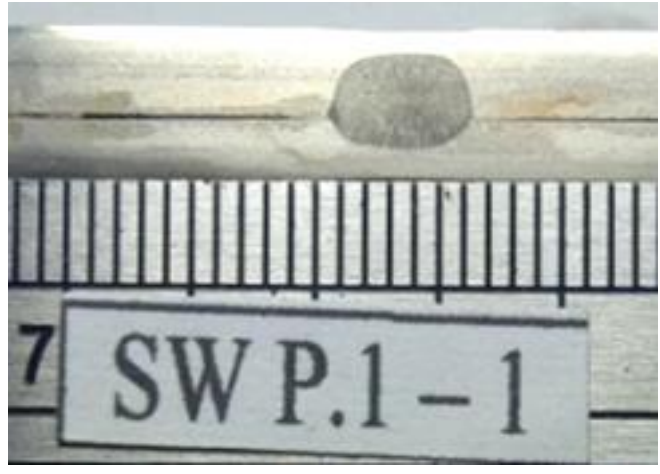

(a)

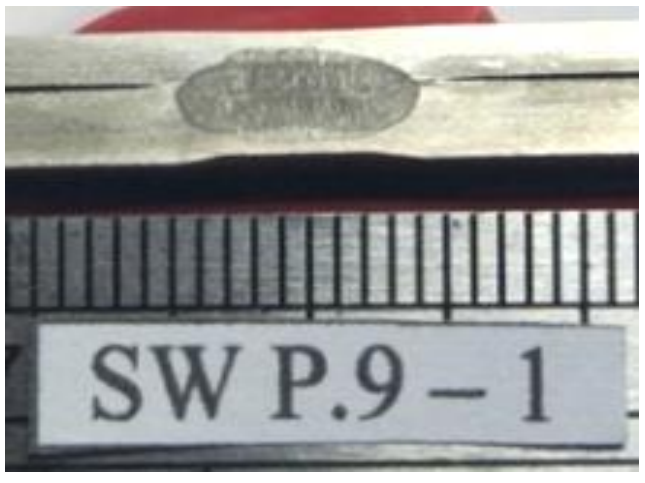

(b)

Gambar 3. Hasil Pengujian Makro (a) Eksperimen 1 (Current 10kA, Weld Time 17 Cycle, Pulsation 0 Time) (b) Eksperimen 9 (Current 11kA, Weld Time 27 Cycle, Pulsation 1 Time)

Dari Gambar 3 dilakukan pengujian dan pengukuran diameter nugget, hasil pengujian secara visual menunjukkan hasil resistance spot welding kedua eksperimen tersebut tidak terdapat cacat dan hasilnya full penetration. Untuk hasil pengukuran menunjukkan untuk panjang diameter nugget eksperimen 1 sebesar $6 \mathrm{~mm}$, sedangkan untuk eksperimen 9 hasil pengukuran diameter nugget sebesar $10 \mathrm{~mm}$. Hasil pengukuran tersebut berdasarkan ASME Section IX dinyatakan diterima, karena sesuai dengan syarat keberterimaan uji makro. Namun jika dari segi kualitas dan kekuatan tarik eksperimen 9 lebih baik dibandingkan eksperimen 1, karena hasil uji tarik eksperimen 9 lebih besar disbanding dengan eksperimen 1. Dari hasil pengujian makro ini dapat disimpulkan juga, jika nilai shear strength semakin tinggi maka diameter nugget semakin panjang. Hal ini dikarenakan semakin besar ukuran diameter nugget maka nilai pengujian shear strength juga semakin meningkat [13]. Selain itu juga weld time yang rendah akan menghasilkan diameter nugget yang kecil, namun jika terlalu tinggi aplikasi weld time yang tinggi juga dapat menurunkan ukuran diameter nugget [14].

\subsection{Pengujian Struktur Mikro}

Pengujian struktur mikro dilakukan dengan tujuan untuk mengetahui struktur yang terjadi setelah proses resistance spot welding. Untuk daerah yang diamati meliputi logam induk, heat affected zone (HAZ) dan logam las. Sama dengan pengujian makro, eksperimen yang dilakukan pengujian struktur mikro adalah eksperimen 1 dan eksperimen 9 . Perbesaran yang dilakukan untuk pengujian struktur mikro pada penelitian ini sebesar 500x. Hasil pengujian struktur mikro daerah logam induk eksperimen 1 dengan variasi (Current 10kA, Weld Time 17 Cycle, Pulsation 0 Time) dapat dilihat pada Gambar 4. Untuk pengujian struktur mikro daerah logam induk eksperimen 9 (Current 11kA, Weld Time 27 Cycle, Pulsation 1 Time) dapat dilihat pada Gambar 5. 
Mochammad Karim Al Amin dkk /Jurnal Rekayasa Mesin

p-ISSN: 1411-6863, e-ISSN: 2540-7678

Vol.16|No.3|359-368|Desember|2021

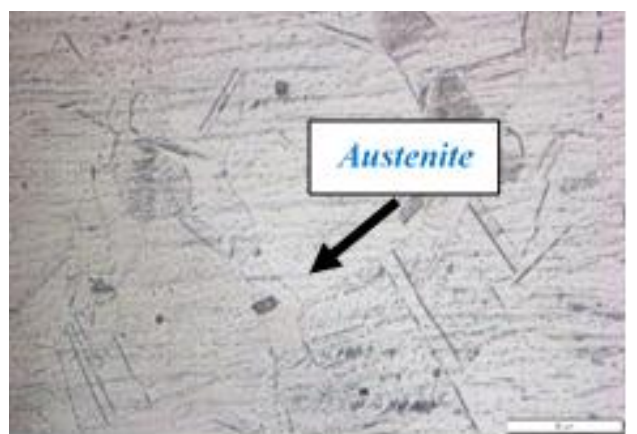

(a)

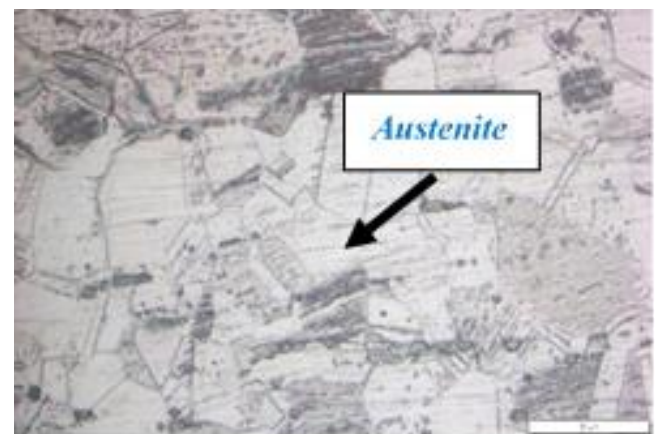

(b)

Gambar 4. (a) Struktur Mikro Base Metal Material SA-240 tipe 201 Eksperimen 1 Perbesaran 500x, (b) Struktur Mikro Base Metal Material SA-240 tipe 304 Eksperimen 1 Perbesaran 500x.

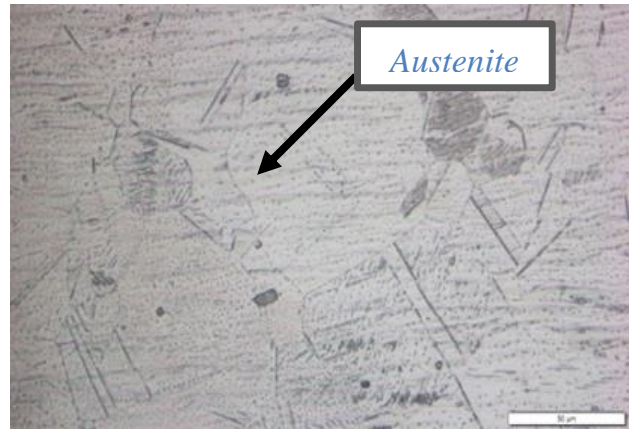

(a)

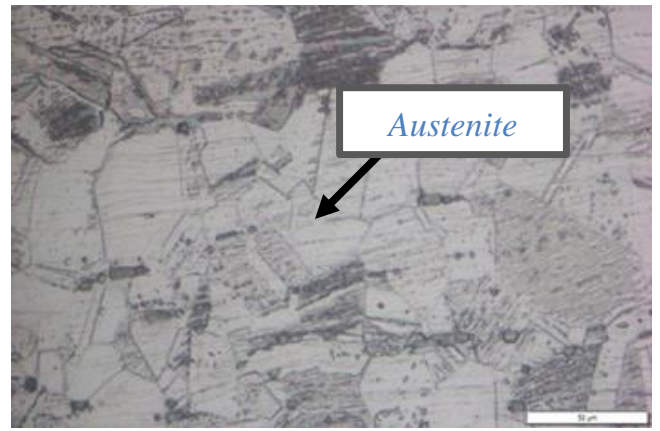

(b)

Gambar 5. (a) Struktur Mikro Base Metal Material SA-240 tipe 201 Eksperimen 9 Perbesaran 500x, (b) Struktur Mikro Base Metal Material SA-240 tipe 304 Eksperimen 9 Perbesaran 500x.

Dari Gambar 4 dan 5 dapat diamati jika pada daerah base metal ini tidak terjadi perubahan struktur, karena daerah base metal tidak mengalami pemanasan dan struktur yang terjadi adalah fasa austenite. Fasa austenite pada base metal mempunyai ciri yaitu terdapat struktur yang memanjang sejajar di daerah grains boundary.

Hasil pengujian struktur mikro yang terjadi pada daerah HAZ eksperimen 1 (Current 10kA, Weld Time 17 Cycle, Pulsation 0 Time) dapat dilihat pada Gambar 6, sedangkan untuk eksperimen 9 (Current 11kA, Weld Time 27 Cycle , Pulsation 1 Time) dapat dilihat pada Gambar 7.

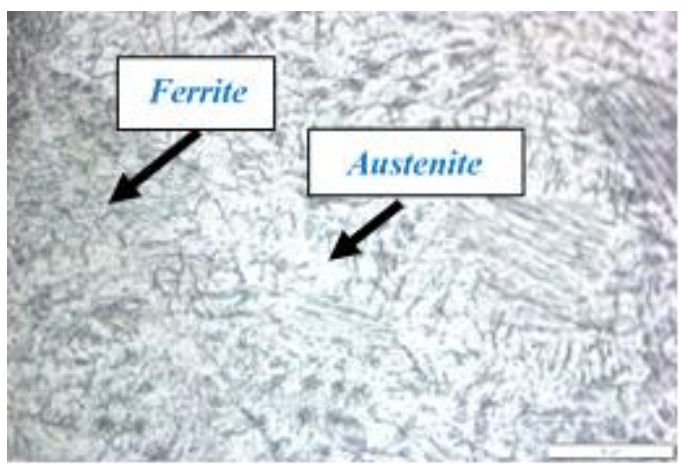

(a)

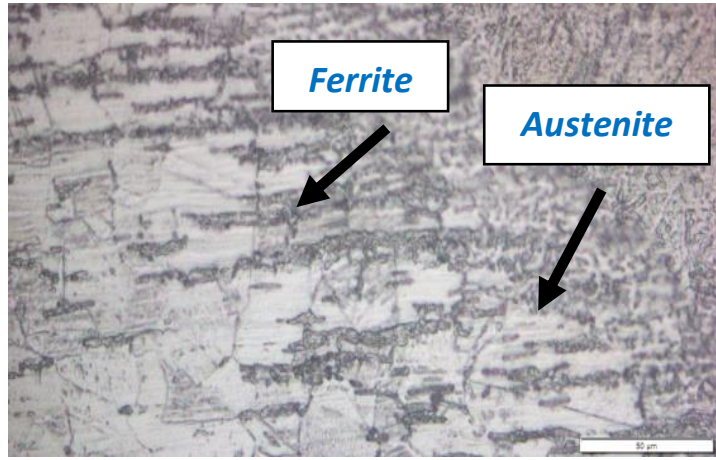

(b)

Gambar 6. (a) Struktur Mikro HAZ Material SA-240 tipe 201 Eksperimen 1 Perbesaran 500x, (b) Struktur Mikro HAZ Material SA-240 tipe 304 Eksperimen 1 Perbesaran 500x. 


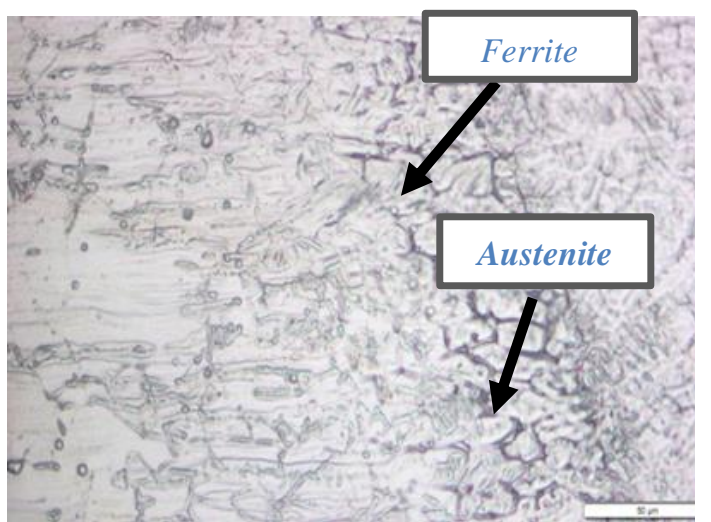

(a)

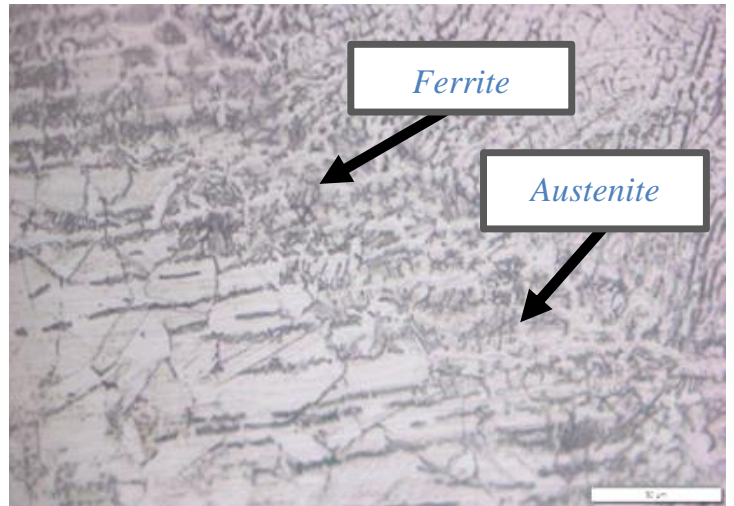

(b)

Gambar 7. (a) Struktur Mikro HAZ Material SA-240 tipe 201 Eksperimen 9 Perbesaran 500x, (b) Struktur Mikro HAZ Material SA-240 tipe 304 Eksperimen 9 Perbesaran 500x.

Dari pengujian struktur mikro eksperimen 1 dan eksperimen 9 tidak terjadi perbedaan yang terlalu signifikan, dan struktur yang terbentuk pada HAZ adalah austenite dan ferrite. Ukuran butir yang terjadi pada daerah yang semakin menjauh dari daerah weld metal maka ukuran butir semakin kecil dan semakin dekat dengan weld metal ukuran butir semakin besar. Struktur mikro pada daerah weld metal dapat dilihat pada Gambar 8.

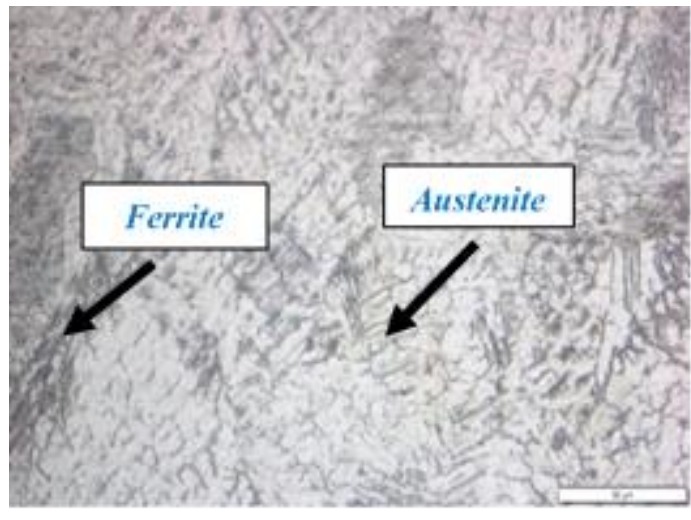

(a)

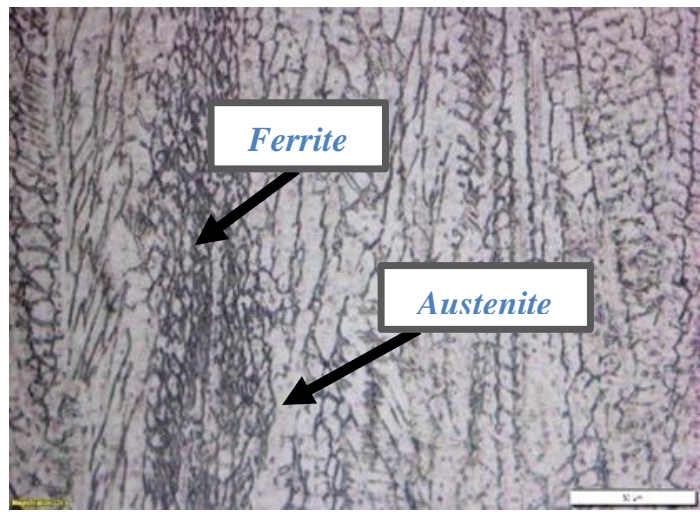

(b)

Gambar 8. (a) Struktur Mikro Weld Metal Eksperimen 1 Perbesaran 500x, (b) ) Struktur Mikro Weld Metal Eksperimen 9 Perbesaran 500x,.

Hasil pengujian struktur mikro pada weld metal menujukkan perbedaan bentuk struktur, eksperimen 9 memiliki bentuk butir yang lebih rapat dibandingkan eksperimen 1. Pada pengujian mikro ini juga menunjukkan jika struktur mikro yang terjadi butirannya memanjang (columnar grains) ke daerah yang mengalami pembekuan paling akhir. Struktur columnar grains yang khas disebabkan oleh pertumbuhan dendritik dari garis fusi selama pemadatan ferit primer [15].

\section{Kesimpulan}

Dari hasil penelitian dan analisis variasi yang telah dilakukan, dapat disimpulkan perubahan parameter resistance spot welding yang meliputi current, weld time dan pulsation akan mempengaruhi hasil pengujian shear strength dan metalografi. Hasil pengujian shear strength menunjukkan bahwa nilai tertinggi terdapat pada eksperimen 9 dengan variasi current sebesar $11 \mathrm{kA}$, weld time 27 cycle dan pulsation 1 time, hal itu sesuai dengan hasil pengujian makro yang menunjukkan bahwa diameter nugget juga eksperimen 9 lebih besar daripada diameter nugget eksperimen 1 dengan 
Mochammad Karim Al Amin dkk /Jurnal Rekayasa Mesin

p-ISSN: 1411-6863, e-ISSN: 2540-7678

Vol.16|No.3|359-368|Desember|2021

variasi current sebesar $10 \mathrm{kA}$, weld time 17 cycle dan pulsation 0 time. Karena semakin besar ukuran diameter nugget maka nilai pengujian shear strength juga semakin meningkat. Hasil pengujian mikro menunjukkan bentuk butir pada eksperimen 9 lebih rapat dibandingkan dengan eksperimen 1, hal ini juga sesuai dengan pengujian shear strength yang menunjukkan eksperimen 9 current sebesar $11 \mathrm{kA}$, weld time 27 cycle dan pulsation 1 time nilai shear strengthnya lebih tinggi dibanding eksperimen 1 current sebesar $10 \mathrm{kA}$, weld time 17 cycle dan pulsation 0 time.

\section{Daftar Pustaka}

[1] K. Biomantara and H. Herdiansyah, "Peran Kereta Api Indonesia (KAI) sebagai Infrastruktur Transportasi Wilayah Perkotaan,” Cakrawala - J. Hum. Bina Sarana Inform., vol. 19, no. 1, pp. 1-8, 2019.

[2] R. Fitriadi and A. Yudiana, "Pentingnya Perancangan Process Instruction Dalam Konsep Desain Produk Pada Departemen Teknologi Produksi," Simp. Nas. Teknol. Terap., pp. 1-13, 2013.

[3] Sumarji, "Studi Perbandingan Ketahanan Korosi Stainless Steel Tipe Ss 304 Dan Ss 201 Menggunakan Metode U-Bend Test Secara Siklik Dengan Variasi Suhu Dan Ph,” J. Rotor, vol. 4, no. 1, pp. 1-8, 2011.

[4] S. Ghunage, B. B. Ahuja, and A. Verma, "Resistance Welding of Austenitic Stainless Steels (AISI 304 with AISI 316)," 5th Int. 26th ALL India Manuf. Technol. Res. Conf. 1-6, Dec. 2014.

[5] Y. Purwaningrum and M. Fatchan, "Pengaruh Arus Listrik Terhadap Karakteristik Fisik-Mekanik Sambungan Las Titik Logam Dissimilar Al-Steel," Rotasi; Vol 15, No 1 Vol. 15, Nomor 1, Januari 2013DO 10.14710/rotasi.15.1.16-22, 2013, [Online]. Available: https://ejournal.undip.ac.id/index.php/rotasi/article/view/4650.

[6] Guidelines For Resistance Spot Welding. Wisconsin, USA: Miller Electric Mfg. LLC, 2018.

[7] H. Haikal and T. Triyono, "Studi Literatur Pengaruh Parameter Pengelasan Terhadap Sifat Fisik Dan Mekanik Pada Las Titik (Resistance Spot Welding)," Rotasi; Vol 15, No 2 Vol. 15, NOMOR 2, April 2013DO 10.14710/rotasi.15.2.44-54 , Apr. 2013, [Online]. Available: https://ejournal.undip.ac.id/index.php/rotasi/article/view/5182.

[8] M. Raut and V. Achwal, "Optimization Of Spot Welding Process Parameters For Maximum Tensile Strength," Int. J. Mech. Eng. Robot. Res., vol. 3, no. 4, pp. 506-517, 2014.

[9] D. Prastya, Mustafa, and Sutrisno, "Pengaruh Variasi Welding Time pada Permukaan Lembaran Baja Tahan Karat SUS 304 yang Mengalami Pengelasan Resistansi Titik," Pros. Semin. Nas. Sains dan Teknol. Terap., pp. 403-408, 2019.

[10] Section IX ASME Boiler and Pressure Vessel Code. New York: The American Society of Mechanical Engineers, 2017.

[11] D. W. Karmiadji and M. K. Huda, "Analisis Pengelasan Spot Welding Pada Material SPC Dan SCGA Kendaraan Mpv,” Pros. Semin. Rekayasa Teknol., pp. 665-678, 2018.

[12] V. K. Prashanthkumar, N. Venkataram, N. S. Mahesh, and Kumarswami, "Process Parameter Selection for Resistance Spot Welding through Thermal Analysis of 2mm CRCA Sheets," Procedia Mater. Sci., vol. 5, pp. 369-378, 2014, doi: https://doi.org/10.1016/j.mspro.2014.07.279.

[13] N. M. Charde, "Effect of spot welding variables on nugget size and bond strength of 304 austenitic stainless steel," Australas. Weld. J. - Weld. Technol. Inst. Aust., vol. 57, p. 6, Jan. 2013. 
[14] N. Akkaş, V. Onar, C. Teke, E. Ilhan, and S. Aslanlar, "Welding Time Effect on Nugget Sizes in Resistance Spot Welding of SPA-C Steel Sheets used in Railway Vehicles,” Acta Phys. Pol. A, vol. 134, pp. 235-237, Jul. 2018, doi: 10.12693/APhysPolA.134.235.

[15] S. Saha, M. Mukherjee, and T. Pal, "Microstructure, Texture, and Mechanical Property Analysis of Gas Metal Arc Welded AISI 304 Austenitic Stainless Steel,” J. Mater. Eng. Perform., vol. 24, pp. 1125-1139, Mar. 2014, doi: 10.1007/s11665-014-1374-0. 